\title{
Representação Social do Usuário de Drogas na Perspectiva de Dependentes Químicos
}

\author{
Juliana Rízia Félix Melo \\ Universidade Federal da Paraíba, PB, Brasil.
}

\author{
Silvana Carneiro Maciel \\ Universidade Federal da Paraíba, PB, Brasil.
}

\begin{abstract}
Resumo: Os usuários de drogas estão ligados a um imaginário que remete à irresponsabilidade e à delinquência; por isso, não há muita disponibilidade para ouvir sobre suas experiências e vivências. Diante disso, objetivou-se conhecer e analisar o conteúdo e a estrutura da representação social do usuário de drogas. A amostra compreendeu 30 dependentes químicos em tratamento numa instituição psiquiátrica em João Pessoa-PB. Foi utilizada uma entrevista, analisada por meio da Análise de Conteúdo Temática, e a Técnica de Associação Livre de Palavras, analisada a partir do EVOC. Os instrumentos foram administrados individualmente no ambiente institucional. Constatou-se que a representação social do usuário de drogas é negativa, pois ele é concebido como não confiável e mau-caráter, e como um doente, não tendo capacidade de lutar contra sua dependência. Conclui-se que essas representações podem ter repercussões negativas na vida desses usuários, pois adquirem status de verdade, guiando suas condutas e a forma como compreendem sua realidade.
\end{abstract}

Palavras-chaves: Drogas, Usuário de drogas, Dependência Química, Representações Sociais.

\section{Drug User's Social Representation in the Perspective of the Chemical Dependent}

\begin{abstract}
Drug users are associated to irresponsibility and delinquency, which makes it difficult for them to be heard. This study sought to know and to analyze the content and structure of drug-user's social representation. The sample included 30 under-treatment drug addicts in a psychiatric institution in João Pessoa-PB. An interview - analyzed by the Thematic Content Analysis -, and a Free Association of Words Technique - analyzed from EVOC - were used. The instruments were individually administrated inside the institutional environment. The drug user's social representation was seen as negative, as he is considered as a bad character, and as a sick and an unreliable person without the capacity of fighting against his addiction. In conclusion, these representations might have negative outcomes on the users' lives as they acquire status of truth, guiding their behaviors and the way they comprehend their realities.

KeYwords: Drugs, Drug user, Drug Addiction, Social Representations.
\end{abstract}




\title{
Representación Social del Usuario de Drogas en la Perspectiva de Dependientes Químicos
}

\begin{abstract}
Resumen: Los usuarios de drogas están ligados a un imaginario que remite a la irresponsabilidad y a la delincuencia; por eso, no hay mucha disponibilidad para oír sobre sus experiencias y vivencias. Ante esto, se buscó conocer y analizar el contenido y la estructura de la representación social del usuario de drogas. La muestra comprendió 30 dependientes químicos en tratamiento en una institución mental en João Pessoa-PB. Fue utilizada una entrevista, analizada por medio del Análisis de Contenido Temático, así como una Técnica de Asociación Libre de Palabras, analizada a partir del EVOC. Los instrumentos fueron administrados individualmente en el ambiente institucional. Se constató que la representación social del usuario de drogas es negativa, pues es concebido como no confiable, de mal carácter, y como un enfermo, no teniendo capacidad de luchar contra su dependencia. Se concluye que esas representaciones pueden tener repercusiones negativas en la vida de esos usuarios, pues adquieren estatus de verdad.

Palabras clave: Drogas, Consumidor de Drogas, Dependencia Química, Representaciones Sociales.
\end{abstract}

\section{Introdução}

A dependência química é um fenômeno que possui um caráter polissêmico, que se manifesta no tempo e no espaço e que possui vínculo estreito com os fatores sociais, como, por exemplo, a pobre$\mathrm{za}$, a desigualdade social e os demais problemas da contemporaneidade. Como aponta Bucher (1988), as modificações, o progresso, os recursos a serviço do homem, as novas formas de miséria e de riqueza têm influência decisiva no problema da droga e na forma de compreendê-lo e preveni-lo.

Essas transformações sociais têm repercussões na forma de se representar as drogas e na imagem dos seus usuários. Estes são entendidos no presente estudo como aqueles indivíduos que possuem uma dependência química de drogas lícitas e, especialmente, ilícitas. Conforme Bucher (1988), esses usuários são concebidos como pessoas que escapam do controle das regras legais e morais da sociedade, não se deixando encerrar no sistema social vigente. Os usuários de substâncias ilícitas, especificamente, furam o circuito comercial autorizado e devidamente tributado, inserindo-se num outro circuito, clandestino ou semioficial. Por conseguinte, transformam-se numa ameaça para esse sistema que, numa atitude de autoproteção, tem de persegui-los como elementos desestabilizadores da sua política e da sua ideologia.

Segundo Oliveira e Dias (2010), os usuários de drogas estão revestidos de um imaginário e de práticas que remetem ao gozo, à irresponsabilidade, à delinquência e à afronta aos hábitos e costumes sociais. Em virtude disso, não há muita disponibilidade da sociedade em geral para ouvir sobre suas experiências e vivências. Como consequência, seu sofrimento, suas demandas e todo o seu mal-estar ficam invisíveis. Pode-se dizer que muito se fala sobre os usuários de drogas, mas pouco se escuta e pouco se faz em prol da sua subjetividade e reinserção social. Pouco se faz em termos de cuidado e de propostas de mudanças, pois o dependente químico ainda é tratado como marginal e como alguém que precisa não só ser punido, mas excluído da sociedade (Nunes, Santos, Fischer, \& Güntzel, 2010).

Lima (2005) destaca que a dependência química corresponde a um fenômeno que não se confunde apenas com o consumo de drogas, mas sim ao encontro de um indivíduo consigo mesmo, com seus valores e crenças. De modo que, a droga, inserida nesse sistema capitalista, num determinado contexto sociocultural, incentiva, carimba e aprisiona o individuo no personagem do viciado, o que impossibilita muitas vezes que ele consiga sua diferenciação. Assim, impõe-se sobre ele a negação de sua experiência pessoal subjetiva e idiossincrática e lhe é atribuído um sentido $a$ priori para a sua vida.

No intuito de ouvir a perspectiva desses usuários, o presente estudo teve como participantes dependentes químicos em tratamento e objetivou conhecer e analisar o conteúdo e a estrutura da representação social do usuário de drogas. O alcance do objetivo proposto pode proporcionar uma melhor compreensão 
dos problemas relacionados ao uso abusivo de drogas, contribuindo para a geração de dados científicos que colaborem no desenvolvimento de estratégias mais eficientes ligadas a essa questão, capazes de abarcar os elementos psicossociais que envolvem esse consumo.

\section{Historiando as drogas}

As drogas podem ser definidas como substâncias não produzidas pelo organismo, que têm a propriedade de agir no cérebro modificando funções mentais, como o julgamento, o humor, a percepção e o comportamento de maneira geral. Como afirma Cruz (2011), suas funções são múltiplas e podem estar ligadas ao desejo do homem de buscar formas de alterar seu estado de consciência, explorar suas emoções, melhorar seu estado de espírito, intensificar a sensação dos sentidos, promover a interação em seu meio social, dentre outras possibilidades de uso. Ressaltese, ainda, que drogas são todos os fármacos, não se limitando somente àquelas substâncias que são alvo de algum controle ou repressão por parte do Estado.

O uso de drogas sempre esteve presente na história da humanidade e, ao longo do tempo, cada sociedade se encarregou de delimitar suas formas de uso, de acordo com o seu contexto cultural. Mesmo levando em consideração o perigo oferecido pelas substâncias, as regras de utilização, suas proibições e liberações foram determinadas histórica e culturalmente (Cruz, 2011). Nesse sentido, observa-se que as drogas nem sempre foram tidas como geradoras de problemas, sendo utilizadas em contextos diversos, como: religioso, místico, social, econômico, medicinal, cultural, psicológico, climatológico, militar e o da busca do prazer.

De acordo com Tinoco (2002), as "ervas", substâncias tidas como desordenadoras dos sentidos e dos estados de consciência, são conhecidas desde as mais primitivas civilizações e culturas. Naquela época, o uso era regido e regulado por códigos culturais que restringiam o uso a momentos de rituais, a épocas específicas do ano e a momentos religiosos, em que o consumo objetivava a comunicação com as esferas divinas. Essas experiências inscreviam o indivíduo numa ordem social que o ultrapassava e que se replicava através de gerações.

Desde a Antiguidade, os gregos e romanos já empregavam vários tipos de drogas, que eram consideradas neutras, pois podiam servir de remédio ou de veneno, dependendo da forma como eram utilizadas. Nessa perspectiva, a substância era interpretada como algo inanimado e o que fazia dela um remédio ou um veneno era o manuseio do homem (Pratta, \& Santos, 2009).

Na Idade Média, o uso das plantas foi condenado pela Igreja Católica, que passou a considerá-las como diabólicas e como sinônimo de feitiçaria. Segundo Mota (2009), a Igreja Católica perseguia religiões pagãs e culturas antigas que utilizavam plantas alucinógenas em seus rituais, pois tais usos objetivavam experiências transcendentes e místicas, em que os indivíduos relatavam falar com os seus deuses. Nesse sentido, o uso dessas substâncias fugia ao controle da Igreja, que pregava que só através da religião cristã podia-se chegar a Deus.

Naquela época, as plantas ficaram estigmatizadas e o seu uso era objeto de perseguição, a tal ponto que o emprego de drogas para fins terapêuticos tornou-se sinônimo de heresia, sendo o sofrimento concebido como uma forma de aproximação a Deus. Conforme Pratta e Santos (2009), o uso de poções e unguentos era condenado pelos tribunais da Inquisição, que puniam com torturas e morte os indivíduos que os utilizavam.

A única droga permitida na Idade Média era o álcool, notadamente o vinho. Embora o seu uso fosse frequente em festividades e rituais religiosos, seu excesso era condenado. No começo do Novo Testamento, é relatado o primeiro milagre de Cristo: a transformação da água em vinho, denotando a ideia da transformação de algo comum em uma boa bebida. Na época do Novo Testamento, existia o costume de beber vinho para saciar a sede, tendo em vista a rápida deterioração da água por causa das dificuldades em relação à sua armazenagem. Assim, o vinho era abençoado pelo seu sabor e por sua utilidade. Até hoje, o vinho é um elemento importante dentro do Cristianismo, fazendo parte dos seus ritos e simbolizando o sangue de Cristo (Mota, 2009).

Como sublinha Mota (2009), a representação das drogas e de seus usuários perpassa o prisma religioso, em que a droga é tida como um mal, a dependência química, vista como algo do Diabo, e o usuário de drogas, possuído por forças malignas que o afastam do "Projeto de Deus" para a vida do homem. O demônio é, assim, o principal indutor dessa prática. O uso de drogas é visto como uma maldição, pecado ou culpa e a fé vista como o único meio de resolução.

Ainda no que refere-se ao uso de drogas no contexto religioso e cultural, segundo Ferreira e Martini (2001), nas grandes civilizações pré-colombianas dos 
Andes, há mais de 4.500 anos, a folha extraída da planta Erythroxylon coca, da qual se faz a cocaína, já era conhecida e utilizada. Numerosas lendas referem-se a ela em associação com os mistérios sagrados da fertilidade, da sobrevivência e da morte, como também de práticas curativas. Para os incas, a planta era sagrada, um presente do deus Sol. Até a chegada dos espanhóis à América, o seu uso era privilégio da nobreza Inca. A quantidade de droga usada pelos índios era bastante baixa. Havia um limite, até mesmo físico, do número de folhas capazes de ser mascadas, servindo como uma segurança contra os efeitos tóxicos da cocaína.

De acordo com Totugui (1988), o ópio era um símbolo mitológico dos antigos gregos e era revestido de um significado divino, sendo os seus efeitos considerados como uma dádiva dos deuses, destinada a acalmar os enfermos. A história mundial do ópio passa pela China e a papoula, planta que fornece o ópio, é um símbolo nacional dos chineses. Na Malásia, era uma tradição entre os pescadores utilizar o ópio para ajudar a suportar as condições de vida difíceis. A maconha era empregada com fins terapêuticos na China, em 1730 a.C., e foi descrita pelo imperador Shen Nung como analgésico. Seu emprego medicinal é uma tradição entre os povos africanos e asiáticos.

No Brasil, o consumo de Hoasca (ou vegetal, para a seita União do Vegetal) ou Ayahuasca (ou daime, para a seita Santo Daime), um chá alucinógeno preparado com o cozimento de ervas, é frequente nos rituais dessas seitas religiosas. Esse consumo é sempre comunitário, acompanhado de muitas músicas para afastar as "visões ruins" (Totugui, 1988).

No contexto medicinal, observa-se que, com o avanço da ciência médica, o uso das drogas firmou-se no tratamento de muitas doenças, em que puderam ser científica e largamente utilizadas. No dizer de Maciel (1997), os avanços da química proporcionaram a descoberta, a síntese e a industrialização de novas drogas ditas terapêuticas, possibilitando o controle das sensações dolorosas. A descoberta das drogas anestésicas repercutiu nos círculos médicos e a popularização da anestesia ampliou a circulação social das já existentes. Isso estimulou a criação de novas drogas anestésicas mais potentes, derivadas da cocaína e do ópio, como a xilocaína e a morfina, respectivamente, alterando a prática médica e pondo por terra a crença de que a dor era inevitável.

De acordo com Ferreira e Martini (2001), as folhas da coca eram levadas da América do Sul para outros países, onde eram transformadas em produtos, contudo, perdia-se muito da concentração de cocaína nas longas viagens. Em 1885, um químico, trabalhando para uma indústria farmacêutica, revolucionou a produção ao descobrir uma maneira de produzir cocaína semirrefinada nos próprios países onde estavam instaladas as fábricas. A partir daí, as viagens e o armazenamento das folhas de coca foram simplificados, os preços caíram e o consumo de cocaína semirrefinada aumentou substancialmente. Dessa forma, houve uma rápida explosão de fábricas de medicações utilizando a cocaína em diversos produtos.

Assim, com a descoberta da fórmula exata da estrutura química da cocaína em 1898 e a sua produção de forma sintética em laboratório, em 1902, essa substância passou a ser considerada como um fármaco milagroso, e os americanos começaram a prescrevê-la para enfermidades particularmente difíceis de tratar. Freud contribuiu de maneira decisiva para a divulgação da nova droga, quando, em 1884, publicou um livro sobre a cocaína no qual defendeu o seu uso terapêutico para diversos males. O próprio Freud fazia uso da cocaína e a recomendava. Entretanto, após quatro anos de sua publicação original, Freud voltou atrás, rendendose às evidências de que a "droga milagrosa" tinha uma série de inconvenientes, começando pelo seu potencial de criar dependência (Ferreira, \& Martini, 2001).

Nessa época, ainda não havia leis ou regulamentos que limitassem a venda ou o consumo da cocaína, e ela tornou-se presente em farmácias, mercearias e bares. Passaram a ser comuns episódios de toxicidade, tolerância, dependência e até mesmo morte pelo uso de produtos derivados da cocaína, os quais passaram a ser relatados em revistas médicas no início dos anos 1920. Os problemas tornaram-se ainda mais frequentes e graves quando, na mesma época, surgiram comercialmente seringas hipodérmicas, facilitando a chegada de uma maior quantidade de cocaína na corrente sanguínea, como apontam Ferreira e Martini (2001).

Assim como ocorreu com a cocaína, a Revolução Industrial propiciou alguns fatores que contribuíram para mudar o padrão do uso das drogas em toda a sociedade. $\mathrm{O}$ primeiro fator refere-se à passagem da fabricação artesanal para a fabricação industrial. A potencialização química do princípio ativo dessas substâncias possibilitou a produção em larga escala, a diminuição dos preços e o acesso por parte de um maior número de pessoas. A introdução de novas tecnologias favoreceu, por exemplo, a produção de bebi- 
das destiladas, com um teor alcoólico muito maior do que o das fermentadas. Antes, as drogas usadas eram naturais, com menor efeito de dependência do que as drogas industrializadas; nesse sentido, drogas como a cachaça e a cocaína são certamente bem mais propensas a desencadear o vício do que os seus equivalentes naturais (Mota, 2009).

Outro fator diz respeito ao fato de que, nesse contexto, as populações passaram a viver em grandes concentrações urbanas, mudando o perfil das relações sociais e o caráter do uso das drogas, agora mais fortes e mais acessíveis. O uso das substâncias psicoativas passou a ser, então, alvo de comercialização para a obtenção de lucros, regido pela dinâmica do capitalismo, que propiciou a industrialização e a massificação desses produtos. Conforme Tinoco (2002), tais fatores contribuíram para tornar o uso de drogas um problema de saúde pública no mundo a partir das últimas décadas do século XIX e início do século XX.

Durante o século $\mathrm{XX}$, fatores importantes que contribuíram para a disseminação das drogas foram as duas guerras mundiais. Como explicita Maciel (1997), era comum serem distribuídas drogas estimulantes nos acampamentos para os soldados, no intuito de diminuir a fadiga e para que eles permanecessem mais tempo em alerta, visando também diminuir as dificuldades de adaptação em uma situação de conflito e permanente tensão. Era frequente o uso de drogas analgésicas, como as derivadas da cocaína, devido aos graves ferimentos dos soldados em combate. Ademais, com o final da guerra, restaram muitos soldados com perturbações psíquicas que procuraram auxílio para os seus problemas no álcool e em outras drogas.

Ainda no século XX, outro fator importante sobre as drogas foi a chamada "cultura pop", liderada pelo movimento hippie, nos anos 1960, em que a droga ocupava um lugar de objeto revolucionário. Esse movimento caracterizava-se pela rejeição ao modo de vida convencional e pela crítica e até rejeição das instituições sociais, como a família, a igreja, a escola e o trabalho. Conforme Maciel (1997), enfatizava-se uma concepção demundo diferente, onde aliberdade sexual, o comunitarismo e o descompromisso com objetos materiais eram marcantes. Havia a oposição à sociedade de consumo e às injustiças sociais. Nesse contexto, as drogas, principalmente a maconha, passaram a ser um símbolo de comportamento independente e expressão de rebelião contra uma sociedade rígida. Todavia, no final da década de 1960, incrementou-se a atuação dos traficantes e o movimento hippie foi engolfado pela ordem social e econômica. A droga foi, então, transformada em material de consumo altamente rentável, perdendo o seu sentido reivindicatório, como aponta Silva (2007).

Outra questão importante a ser destacada quando se fala de drogas é a política proibicionista. No começo do século XX, começaram nos Estados Unidos algumas movimentações no sentido de criar regulamentações sobre as drogas, lideradas por grupos de igrejas e associações protestantes. Iniciava-se, assim, o movimento proibicionista, que era ligado a concepções religiosas que condenavam o uso de drogas (Oliveira, 2009).

Tendo como pano de fundo essa política, o aparato jurídico-institucional brasileiro estabelecido ao longo do século XX destinava-se, principalmente, ao controle do consumo de drogas tornadas ilícitas. Constituído por uma série de leis e decretos que proibiam e criminalizavam o uso e o comércio de drogas no país, esse aparato previa penas que determinavam a exclusão dos usuários do convívio social, propondo a sua permanência em prisões, sanatórios e, a partir da década de 1970, em hospitais psiquiátricos, como destacam Machado e Miranda (2007).

Assim, a legislação brasileira sobre as drogas passou a ser influenciada pela medicina a partir da década de 1970, a qual, desde o começo do século XX, apoiou o controle legal sobre as substâncias, posto que favoreceria a sua consolidação como saber científico, ficando sob sua égide exclusiva o receituário e a manipulação de tais substâncias. Nesse ínterim, toda a experiência da medicina popular foi rotulada como misticismo ou charlatanismo, cabendo só aos médicos receitar medicamentos. Ao Estado caberia coibir a prática médica ilegal e controlar as substâncias banidas, passando à medicina seu aval definitivo na promoção da saúde da população (Fiore, 2004).

Em função disso, como apontam Oliveira e Dias (2010), os indivíduos que usavam as drogas tornadas ilícitas passaram a ser considerados, de forma delimitada pelos saberes médico-psiquiátricos e jurídico-policiais, como sendo doentes ou criminosos. Sob a justificativa da neutralidade científica, o tema das drogas passou a pertencer a esses dois sistemas, restringindo as possibilidades de inserção do tema em outros campos e determinando a forma como ele deveria ser abordado.

Desse modo, percebe-se que o uso de drogas constitui um fenômeno atrelado à medicina e ao 
poder jurídico. Os saberes e as práticas médicas legitimam a partilha moral entre as substâncias lícitas e as ilícitas, balizados pela força da sua autoridade científica, historicamente constituída pela sociedade (Vargas, 1998). Por sua vez, o Estado legitima o controle social das drogas, através de um aparato institucional respaldado pela lei, que divide as drogas entre legais e ilegais. Assim, a separação das drogas entre lícitas e ilícitas não é algo natural ou baseado no poder de dependência ou de maleficência das drogas. Essa separação é determinada socialmente e respaldada pela lógica capitalista, de forma que, aos que fazem uso de drogas ilegais, é delegado um tratamento de ordem moral e legal. A ilegalidade da droga associa-se à concepção do indivíduo como um marginal, criminoso e sem caráter. Logo, o usuário dependente de drogas ilícitas é considerado, a um só tempo, como doente e criminoso (Oliveira, \& Dias, 2010).

Diante dos “desviantes", é criado um sistema de acusação, favorecendo a manutenção de certos poderes discriminatórios, pois tais indivíduos funcionam como "bodes expiatórios", que servem para justificar grande parte das mazelas da sociedade. Para isso, adota-se um aparato institucional respaldado por lei, com a possibilidade de punição e coerção. Dessa maneira, os usuários de drogas passaram a ser considerados como pessoas que atentam contra a moral e os bons costumes e também contra as próprias instituições, já que são vistos como causas dos problemas de toda a sociedade, o que os transforma em seres antissociais. Desse lugar de exclusão, o usuário e a droga são culpabilizados pelas tragédias familiares e pela violência, como apontam Bucher e Oliveira (1994).

Diante do exposto, percebe-se que a dependência química e, notadamente, a figura do usuário de drogas, são questões de grande repercussão na contemporaneidade, mobilizando afetos, suscitando polêmicas e controvérsias. Em função disso, podem ser considerados como objetos de representação social, pois, segundo Moscovici (2011), uma representação social é o sinal e a reprodução de um objeto socialmente valorizado.

\section{A Teoria das Representações Sociais}

A Teoria das Representações Sociais (TRS) foi proposta por Serge Moscovici em 1961, por meio da obra La Psychanalyse, son image et son public. De acordo com Jodelet (2001, p. 22), as representações sociais são:

\begin{abstract}
Uma forma de conhecimento, socialmente elaborada e partilhada, com um objetivo prático, e que contribui para a construção de uma realidade comum a um conjunto social. Igualmente designada como saber de senso comum ou ainda saber ingênuo, natural, esta forma de conhecimento é diferenciada, entre outras, do conhecimento científico.
\end{abstract}

Assim, as representações sociais constituem uma forma de conhecimento específica e irredutível a qualquer outra. Trata-se de um conceito que explica a diversidade do pensamento em organizações sociais particulares, onde os conteúdos do conhecimento científico passaram a circular (Castro, 2002).

Convém destacar que a TRS desdobra-se em algumas correntes teórico-metodológicas. As principais são as abordagens dimensional, estrutural e societal. O presente estudo baseia-se nas abordagens dimensional e estrutural da TRS, uma vez que se preocupa em conhecer o conteúdo e a estrutura da representação social do usuário de drogas.

De acordo com Arruda (2002), a abordagem dimensional se caracteriza pelo estudo dos conteúdos representacionais, abarcando a totalidade de expressões, ideias, imagens e valores que circulam no discurso sobre o objeto. Além disso, ocupa-se com os processos de construção da representação, em que se destacam dois processos: a objetivação e a ancoragem.

A ancoragem é um mecanismo que tenta aproximar ideias estranhas, reduzindo-as a categorias e a imagens comuns, colocando-as em um contexto familiar. É um processo que compara algo estranho com um paradigma de uma categoria que $o$ ator social pensa ser apropriada. No momento em que determinado objeto ou ideia é comparado ao paradigma de uma categoria, adquire características dessa categoria e é reajustado para que se enquadre nela. Assim, uma pessoa religiosa, por exemplo, procura relacionar um comportamento estranho a uma escala religiosa de valores. Já a objetivação é o processo pelo qual os elementos constituintes da representação se organizam e adquirem materialidade, tornando o abstrato concreto. A objetivação faz com que se torne real um esquema conceptual, conferindo-se, a uma imagem, uma contrapartida material (Melo, \& Maciel, 2014; Moscovici, 2011).

Assim, a abordagem dimensional está preocupada fundamentalmente com o conteúdo de uma representação, tentando apreender os diferentes momentos e movimentos da sua elaboração. Contudo, 
para Abric (1996, 2001a, 2001b) não basta conhecer o conteúdo de uma representação para defini-la, sendo preciso identificar o seu núcleo central, pois este é quem lhe dá significado e quem rege a sua transformação. Nesse sentido, duas representações podem possuir o mesmo conteúdo, mas ter significações diferentes em virtude da sua estrutura. Dessa forma, evidencia-se a abordagem estrutural da TRS.

De acordo com Abric (2001a), as representações sociais são formadas por dois componentes: o núcleo central e os elementos periféricos. Essa organização é governada por um duplo sistema, denominado sistema central e sistema periférico, que formam a estrutura da representação social. O sistema central é composto pelo núcleo central da representação, que tem como característica principal o fato de ser marcado e determinado pelas condições históricas, sociológicas e ideológicas, estando, portanto, fortemente enraizado na memória coletiva de um grupo e balizado pelo seu sistema de normas e valores. Por conseguinte, o núcleo central é estável, resistente à mudança e coerente, e é o responsável pela continuidade, consistência e permanência da representação. Ele representa a base comum e consensual da representação social, sendo a homogeneidade do grupo social arquivada e definida através dele. Além disso, caracteriza-se por ser relativamente independente do contexto material e do contexto social imediato, nos quais a representação é posta em evidência (Abric, 1996, 2001a; Melo, \& Maciel, 2014).

Abric (2001b) atribui aos estudos de Flament a complementação da teoria do núcleo central, tendo em vista que esse autor demonstrou a importância e o papel dos elementos periféricos na estrutura da representação. Assim, enquanto o sistema central é essencialmente normativo, o sistema periférico se caracteriza por sua funcionalidade, pois é regido por fatores do contexto imediato, atualizando e contextualizando constantemente as determinações normativas dos elementos centrais. Tendo um caráter mais sensível, heterogêneo e flexível, o sistema periférico é a interface entre o sistema central e a realidade concreta. Sem ele, a representação não poderia estar enraizada na realidade do momento, logo, o sistema periférico é um complemento indispensável do sistema central (Abric, 1996, 2001a).

A postulação desses dois sistemas, central e periférico, permite a compreensão das representações sociais como um mecanismo de adaptação sociocognitiva.
Isto porque a realidade apropriada e reestruturada pelo indivíduo ou grupo constitui a realidade em si, sendo essa realidade reconstruída pelo seu sistema cognitivo e integrada ao seu sistema de valores. Pode-se considerar, portanto, que existe uma indissociabilidade entre a experiência subjetiva e a inserção social dos sujeitos (Abric, 2001a; Melo, \& Maciel, 2014).

Com base nisso, pode-se compreender as representações sociais do usuário de drogas como uma interpretação coletiva da realidade vivida e falada por esse grupo social, direcionando comportamentos $\mathrm{e}$ comunicações. Assim, o presente estudo objetivou conhecer e analisar o conteúdo e a estrutura da representação social do usuário de drogas, elaborada por dependentes químicos em tratamento.

\section{Método}

Trata-se de um estudo descritivo, com ênfase na abordagem qualitativa. A amostra compreendeu 30 usuários de drogas em tratamento, do sexo masculino, com idade superior a 18 anos, com escolaridade, renda e estado civil variados. Trata-se de uma amostra não probabilística, de tipo acidental. Os critérios para a inclusão na amostra foram: a) ser usuário de drogas em tratamento e b) ter mais que 18 anos. O estudo foi realizado em uma instituição psiquiátrica, na cidade de João Pessoa - PB. Esta instituição oferece atendimento para pacientes com severos transtornos mentais e usuários de múltiplas drogas.

Foram utilizados dois instrumentos: o primeiro foi uma entrevista semiaberta, a qual foi analisada por meio da Análise de Conteúdo Temática proposta por Bardin (1977). O segundo instrumento utilizado foi a Técnica de Associação Livre de Palavras, que consiste em solicitar aos sujeitos que digam as palavras ou expressões que lhes venham imediatamente à lembrança, quando for apresentado um estímulo indutor dado pelo pesquisador, normalmente o próprio rótulo verbal que designa o objeto representacional (Nóbrega, \& Coutinho, 2011). Neste estudo foi utilizado o estímulo indutor usuário de drogas.

Os dados da Associação Livre de Palavras foram analisados por meio do programa computacional Ensemble de programmes permettant l'analyse des evocations-Evoc, querealiza uma análise lexicográfica, combinando-se a frequência de emissão das palavras e/ou expressões com a ordem em que estas são evocadas. O Evoc organiza as palavras evocadas em quadrantes, demonstrando graficamente as palavras 
que pertencem ao núcleo central e ao sistema periférico das representações sociais. O gráfico apresentado pelo Evoc é chamado de quadro de quatro casas. Esta técnica consegue dar conta da identificação da estrutura de uma representação social.

Esta pesquisa atendeu às determinações da Resolução no 196/96, do Conselho Nacional de Saúde. Foi devidamente aprovada pelo Comitê de Ética em Pesquisa, do Centro de Ciências da Saúde da Universidade Federal da Paraíba - CEP/CCS, sob o Protocolo $\mathrm{n}^{\circ}$. 0235/11. Os instrumentos foram administrados individualmente numa sala reservada na própria instituição. Os dados foram gravados e posteriormente transcritos para a análise.

\section{Resultados e discussão}

A seguir serão apresentados e discutidos primeiramente os resultados advindos da Associação Livre de Palavras referentes à análise da estrutura da representação social do usuário de drogas, posteriormente serão apresentados os resultados advindos da Análise de Conteúdo. A Tabela 1 contém os quadrantes relativos ao sistema central e ao sistema periférico.

A Tabela 1 foi construída a partir da frequência média igual, maior ou menor do que cinco participantes, numa ordem média de evocação em torno de 2,7. No quadrante superior esquerdo encontram-se as

Tabela 1

Quadrante das evocações acerca do estímulo usuário de drogas.

\begin{tabular}{|c|c|c|c|c|c|}
\hline \multicolumn{3}{|c|}{ Núcleo Central } & \multicolumn{3}{|c|}{$\begin{array}{l}\text { Sistema Periférico } \\
\text { Próximo }\end{array}$} \\
\hline \multicolumn{3}{|c|}{$\mathrm{f} \geq 5 \mathrm{OME}<2,7$} & \multicolumn{3}{|c|}{$\mathrm{f} \geq 5$ OME $\geq 2,7$} \\
\hline Evocações & $\mathrm{f}$ & OME & Evocações & $\mathrm{f}$ & OME \\
\hline Crack & 5 & 2.2 & Destruição & 5 & 3.4 \\
\hline Maconha & 6 & 2.16 & & & \\
\hline \multicolumn{3}{|c|}{$\begin{array}{l}\text { Sistema Periférico } \\
\text { Próximo }\end{array}$} & \multicolumn{3}{|c|}{$\begin{array}{l}\text { Sistema Periférico } \\
\text { Distante }\end{array}$} \\
\hline \multicolumn{3}{|c|}{$\mathrm{f}<5 \mathrm{OME}<2,7$} & \multicolumn{3}{|c|}{$\mathrm{f}<5$ OME $\geq 2,7$} \\
\hline Evocações & $\mathrm{f}$ & OME & Evocações & $\mathrm{f}$ & OME \\
\hline \multirow{4}{*}{$\begin{array}{l}\text { Perde a } \\
\text { confiança }\end{array}$} & 4 & 2.5 & Cocaína & 4 & 3.75 \\
\hline & & & $\begin{array}{l}\text { Falta de } \\
\text { atenção }\end{array}$ & 4 & 3.75 \\
\hline & & & Sem caráter & 4 & 3.5 \\
\hline & & & Tristeza & 4 & 2.75 \\
\hline
\end{tabular}

f: frequência; OME: Ordem Média das Evocações. palavras crack e maconha. Estas evocações dizem respeito, provavelmente, ao núcleo central da representação social do usuário de drogas, e são responsáveis pela estabilização das representações sociais desse objeto. Tais evocações expressam uma despersonalização desses indivíduos, uma vez que esta representação não está objetivada nas características de uma pessoa que usa drogas, mas nas próprias drogas; nesse sentido, o indivíduo é confundido com a própria substância.

Essa questão é assinalada por Mota (2009), quando afirma que o termo "droga", designado principalmente para referir-se às drogas ilícitas, conduz a uma representação moral da substância, que, por sua vez, é automaticamente transferida aos seus usuários. O status de ilegalidade da substância é projetado na personalidade do usuário. Essa representação traz uma série de implicações que solidificam a exclusão social do usuário. Ela estimula o seu isolamento social, aumentando a dificuldade de conseguir tratamento médico para deixar a dependência da droga ou para tratar os efeitos do seu uso abusivo.

No sistema periférico intermediário da representação social do usuário de drogas, no espaço superior direito, foi evocada a expressão destruição da família. No espaço inferior esquerdo, ainda no sistema periférico intermediário, foi evocada a frase perde a confiança. Em contraste com o núcleo central, no sistema periférico distante, representado no quadrante inferior direito, foram evocadas as palavras cocaína, falta de atenção, sem caráter e tristeza.

Estes elementos do sistema periférico são responsáveis pela concretização do sistema central, no que se refere a tomadas de posição e de condutas (Abric, 2001a), assim, orientam as práticas dos usuários do presente estudo. Desse modo, desdobram a conotação negativa dos elementos do núcleo central da representação social do usuário de drogas.

As evocações falta de atenção e tristeza objetivam o usuário de drogas como um ser frágil e vulnerável, passivo diante da droga. Os termos perde a confiança, destruição da família e sem caráter referem-se à concepção do usuário de drogas como alguém que não merece a confiança das pessoas, que não tem caráter, que é moralmente desqualificado e culpado pela destruição de sua família. Este último aspecto também foi constatado em pesquisa realizada por Medeiros, Maciel, Sousa, Tenório-Sousa e Dias (2013) com familiares de usuários de drogas, na qual os familiares 
representaram a droga como um símbolo de situações de conflito e desarmonia familiar.

Essas questões também foram observadas no estudo realizado por Oliveira (2009), em que se verificou que, no discurso hegemônico sobre o usuário de drogas, prevalece a representação de que o indivíduo évítima da droga, algoz da família, perigoso para si mesmo e para a sociedade. Os diversos atravessamentos existentes em sua vida não são foco de interesse. O usuário de drogas é descrito como uma pessoa a quem deve ser dirigida uma série de intervenções, sendo um misto de delinquente, pois furta, ameaça e agride, e doente mental, já que não tem controle sobre suas ações.

Este último elemento da representação do usuário de drogas, o aspecto que o liga à doença mental, remete à incapacidade atribuída a ele de lutar contra o seu estado de dependência, justificando estratégias de tratamento, como a internação. De acordo com Santos, Acioli Neto e Sousa (2012), ao situar o usuário como sujeito desprovido de capacidade avaliativa de sua própria condição e de sua relação com a droga, pode-se recair em práticas paternalistas e/ou violentas em relação aos usuários. Atualmente, percebe-se que essas práticas misturam aspectos de tratamento de saúde com punição, isto é, um tratamento-punição. Caso não haja tratamento disponível, práticas extremas como a de acorrentamento são aceitáveis, pois demonstram a força necessária para conter o usuário.

$\mathrm{Na}$ pesquisa conduzida por Oliveira (2009), constatou-se que a internação fechada por tempo prolongado é considerada como o tratamento ideal e a única alternativa para todos os usuários de drogas. Tal concepção parece ser uma reedição das práticas asilares voltadas às pessoas com doença mental, e da forma como foram concebidos os tratamentos dos usuários de drogas, de acordo com as políticas sobre drogas construídas ao longo do século XX. Contudo, esse ideal de que a internação prolongada é o melhor tratamento leva um contingente cada vez maior de pessoas a uma situação de frustração. Apesar da sua questionável efetividade enquanto recurso que proporcione a cura, as pessoas tendem a acreditar nessa promessa de melhor tratamento, mas dificilmente terão acesso a ele, pois a oferta por meio da rede de saúde pública é deficitária.

Os elementos representacionais acerca do usuário de drogas encontrados no presente estudo também foram encontrados em uma pesquisa feita por Oliveira (2008), com profissionais que atuam numa unidade básica da rede pública de saúde. Pode-se inferir, portanto, que tais representações tanto influenciam a forma como esses profissionais exercemsua prática comosusuários de drogas, quanto influenciam as práticas desses usuários, favorecendo o distanciamento deles dos serviços públicos de saúde, uma vez que não se sentem cidadãos ao ponto de usufruírem desses equipamentos.

Com vistas a um maior aprofundamento na compreensão da representação social do usuário de drogas para dependentes químicos em tratamento, foram analisados os resultados da Análise de Conteúdo Temática, os quais serão apresentados na Tabela $2 \mathrm{e}$ exemplificados por meio das falas dos participantes. A Tabela 2 mostra as categorias sobre a representação social do usuário de drogas.

Conforme pode ser observado na Tabela 2, o usuário de drogas foi representado como alguém não confiável " Ele não é de confiança não, pode ser o melhor que tem, mas não tem confiança”; "Gente que dá trabalho à sociedade"; "É um ladrão"); viciado (“É um viciado"); sem valor ("Algumas pessoas acham que a gente é um Zé ninguém"; "É uma pessoa que não tem valor de nada”); doente ("O usuário de drogas é um doente"); sofredor ("Para mim o usuário de drogas é uma pessoa muito sofrida"; "Uma pessoa angustiada"; "Se sente só"). Esses resultados confirmam os dados encontrados na estrutura da representação social do usuário de drogas, pois enfocam a ideia de um indivíduo considerado não confiável e mau caráter. Estes dados estão em conformidade com pesquisa realizada por Vargas, Bittencourt, Rocha e Oliveira (2013) com enfermeiros de um CAPS AD, que representaram o dependente químico como acometidos por uma doença, indivíduos que possuem dificuldade de limites, que são manipuladores e responsáveis pelo desenvolvimento da própria dependência.

Tabela 2. Frequências e porcentagens das categorias sobre a representação social do usuário de drogas.

\begin{tabular}{lcc}
\hline Categorias & $\mathrm{f}$ & $\%$ \\
\hline Não confiável & 44 & 31 \\
Viciado/drogado & 39 & 28 \\
Sem valor/ignorado & 29 & 21 \\
Doente & 18 & 13 \\
Sofredor & 11 & 8 \\
Total & 141 & 100 \\
\hline
\end{tabular}

f: frequência. 
Essas representações têm como base a política proibicionista, a qual, com a criminalização do uso de drogas, fortaleceu a vinculação da figura do usuário com o criminoso e bandido, havendo a judicialização do uso de drogas. Nesse enfoque, a figura do usuário de drogas é objetivada por meio de termos que o relacionam ao exemplo do fora da lei, do criminoso, do marginal, do delinquente, do indivíduo socialmente perigoso.

Com o estabelecimento da medicina, houve a institucionalização do usuário para o tratamento médico e sua categorização como um doente, tornando-o objeto da psiquiatria. Sendo assim, o usuário passou a ser objetivado como um doente, viciado, desajustado ou perturbado mental, o que o discrimina e estigmatiza mais ainda, pois além de ele ser rotulado de "perigoso" é percebido também por meio da figura de um "doente mental", o qual é semelhantemente estigmatizado e excluído pela sociedade (Maciel, 1997).

Portanto, observa-se que as representações sociais acerca dos usuários de drogas, elaboradas pelos participantes do presente estudo, foram construídas por meio da apropriação do saber científico associado com o conhecimento do senso comum. Notadamente, essa apropriação se deu no terreno jurídico e médico-psiquiátrico, bem como nas práticas interativas cotidianas.

Destaque-se que essas representações, as quais são hegemônicas na sociedade, foram apreendidas pelos próprios usuários, de modo que esses estereótipos ligados ao usuário/dependente de drogas influenciam na formação da sua autoimagem. Acerca disso, Pérez-Nebra e Jesus (2011) afirmam que as pessoas tendem a acreditar nos estereótipos acerca delas mesmas e se comportam como se eles fossem verdadeiros. Dessa maneira, endossam os estereótipos grupais, transformando-os em descrições de suas identidades. Muitas vezes, isto ocorre por profecias autorrealizadoras, em que as crenças afetam os comportamentos no sentido de aumentar as chances de ocorrer aquilo em que se acredita ou que se teme. Assim, essas representações ganham status de verdade, guiando as condutas dos sujeitos e sendo a forma por meio da qual eles explicam e compreendem sua realidade.

Nesse sentido, representações negativas, como, por exemplo, a de alguém não ser confiável, pode gerar no sujeito um sentimento de incapacidade para o trabalho, para cuidar de objetos de valor, para ter responsabilidades ou, até mesmo, sentimento de incapacidade em levar o seu tratamento adiante. Tais representações podem afetar a sua autoestima, influenciando no sentido de dificultar o enfrentamento da dependência e o sucesso do tratamento. Portanto, essa representação negativa do usuário de drogas, pelo próprio usuário, é como uma marca que ele carrega e que traz sérias consequências para sua inserção social e familiar.

\section{Considerações finais}

Tendo em vista a importância do debate sobre a dependência química nos dias atuais, o presente estudo objetivou conhecer e analisar o conteúdo e a estrutura da representação social do usuário de drogas, elaborada por dependentes químicos em tratamento. Constatou-se que o usuário de drogas é representado negativamente, pois é confundido com a própria droga, com todas as cargas negativas que daí advém, como estigmatização, preconceito e discriminação. Assim, há em certa medida uma despersonalização desse indivíduo, em que ele é objetivado numa coisa inanimada; isto significa que o ser dependente de drogas faz com que o sujeito seja resumido a isso, a essa condição, como se ele não fosse nem pudesse ser mais nada além de estar ligado à droga.

Tal panorama culmina resumidamente na atribuição de dois elementos representacionais negativos: por um lado, o que liga o usuário de drogas a alguém sem caráter, sem escrúpulo, por meio de objetivações como mau-caráter e não confiável e, por outro lado, a percepção desse indivíduo como um doente, um coitado, uma pessoa que é vítima e que, por isso, não tem capacidade de avaliar sua condição perante a droga, nem de lutar contra a sua dependência.

As representações encontradas no presente estudo revelam a existência de um ciclo, no qual os estereótipos e as concepções negativas que a sociedade construiu a respeito dos usuários de drogas são apropriados e reconstruídos por esses usuários, de modo a possibilitar a sua permanência. Nesse sentido, as representações que os usuários de drogas possuem acerca deles mesmos reafirmam o estigma social a eles atribuído, dando continuidade ao ciclo de exclusão social a que estão sujeitos. Diante disso, é preciso compreender que qualquer trabalho ético e de qualidade que envolva o fenômeno das drogas requer o máximo possível de afastamento dos preconceitos e dos estigmas associados a essa questão.

Assim, são necessárias políticas públicas efetivas que tenham como ênfase a prevenção e a pro- 
moção da saúde, com vistas a influenciar a diminuição do abusivo de drogas. É preciso, ainda, que haja reflexões acerca da dependência de drogas, a partir da compreensão da sociedade como um todo, da posição onde se encontra o usuário de drogas nessa sociedade, bem como da função que as drogas desempenham nela, visando uma análise e abordagem multidimensional apropriada para esse complexo fenômeno. Faz-se necessário também um trabalho de intervenção com os próprios usuários, no sentido de favorecer a mudança das suas representações acerca deles mesmos, para que haja o for-

\section{Referências}

Abric, J. C. (1996). Specific processes of social representations. Paperson Social Representations, 5(1), 77-80.

Abric, J. C. (2001a). A structural approach to social representations. In K. Deaux, \& G. Philogène (Eds.), Representations of the social (pp. 42-47). Oxford: Blackwell.

Abric, J. C. (2001b). O estudo experimental das representações sociais. In D. Jodelet (Org.), As representações sociais (pp.155-172). Rio de Janeiro, RJ: UERJ.

Arruda,A. (2002).Ateoria dasrepresentações sociaiseteorias de gênero. Cadernos de Pesquisa, (117), 127-147. doi:10.1590/S0100-15742002000300007

Bardin, L. (1977). Análise de conteúdo. São Paulo, SP: Martins Fontes.

Bucher, R. (1988). As drogas e a vida: uma abordagem biopsicossocial. São Paulo, SP: EPU.

Bucher, R., Oliveira, S. (1994). O discurso do "combate às drogas" e suas ideologias. Revista de Saúde Pública, 28(2), 137-45. doi:10.1590/S0034-89101994000200008

Castro, P. (2002). Notas para uma leitura da teoria das representações sociais em S. Moscovici. Análise Social, 37(164), 949-979. Recuperado de http://www.jstor.org/stable/41011617

Cruz, M. S. (2011). Estratégias de redução de danos para pessoas com problemas com drogas na interface dos campos de atuação da justiça e da saúde. In A. G. Andrade (Coord.), Integração de competências no desempenho da atividade judiciária com usuários e dependentes de drogas (pp. 271-306). Brasília, DF: Ministério da Justiça.

Ferreira, P. E. M., \& Martini, R. K. (2001). Cocaína: lendas, história e abuso. Revista Brasileira de Psiquiatria, 23(2), 96-9. doi:10.1590/S1516-44462001000200008 talecimento da sua postura perante a dependência, contribuindo, assim, para a construção de novos lugares sociais para esses sujeitos.

Destaque-se que diante da amplitude do fenômeno das drogas na sociedade, este estudo foi pontual, não pretendendo esgotar a temática. Sugere-se a realização de novas pesquisas, que aprofundem as questões abordadas, investiguem também construtos como a motivação para o tratamento e a autoestima nessa população, além de estudos que contemplem a estruturação da rede de assistência aos usuários de drogas e seus familiares.

Fiore, M. (2004). Tensões entre o biológico e o social nas controvérsias médicas sobre uso de "drogas". In Anais da 28a. Reunião Anual da ANPOCS. Caxambu, MG: ANPOCS.

Jodelet, D. (2001). Representações sociais: um domínio em expansão. In D. Jodelet (Org.), As representações sociais (pp.17-41). Rio de Janeiro, RJ: UERJ.

Lima, A. F. (2005). A dependência de drogas como um problema de Identidade: possibilidades de apresentação do 'Eu' por meio da Oficina Terapêutica de Teatro [Dissertação de Mestrado]. Pontifícia Universidade Católica de São Paulo, São Paulo, SP.

Machado, A. R., \& Miranda, P. S. C. (2007). Fragmentos da história da atenção à saúde para usuários de álcool e outras drogas no Brasil: da Justiça à Saúde Pública. História, Ciências, Saúde - Manguinhos, 14(3), 801-821. doi:10.1590/S0104-59702007000300007

Maciel, S. C. (1997). Representação social sobre drogas e seus usuários: um estudo comparativo com profissionais das áreas jurídica e de saúde (Dissertação de Mestrado não publicada). Universidade Federal da Paraíba, João Pessoa, PB, Brasil.

Medeiros, K.T., Maciel, S. C., Sousa, P.F., Tenório-Souza, F. M., \& Dias, C. C. V. (2013). Representações sociais do uso e abuso de drogas entre familiares de usuários. Psicologia em Estudo, 18(2), 269-279. doi:10.1590/S1413-73722013000200008

Melo, J. R. F., \& Maciel, S. C. (2014). Representações sociais do crack elaboradas por usuários em tratamento. Psicologia em Estudo, 20(1), 23-32. doi:10.4025/psicolestud.v20i1.23989

Moscovici, S. (2011). Representações sociais: investigações em psicologia social (7a ed.). Petrópolis, RJ: Vozes.

Mota, L. (2009). Dependência química e representações sociais: pecado, crime ou doença?Curitiba, PR: Juruá. 
Nóbrega, S. M., \& Coutinho, M. P. L. (2011). O teste de associação livre de palavras. In M. P. L. Coutinho, \& E. R. A. Saraiva (Orgs.), Métodos de pesquisa em psicologia social:perspectivas qualitativas equantitativas (pp. 95-106). João Pessoa, PB: Editora Universitária.

Nunes, D. C., Santos, L. M. B., Fischer, M. F. B., \& Güntzel, P. (2010). “...outras palavras sobre o cuidado de pessoas que usam drogas...”. In L. M. B. Santos (Org.), Outras palavras sobre o cuidado de pessoas que usam drogas (pp. 15-26). Porto Alegre, RS: Ideograf.

Oliveira, D. C. (2009). Uma genealogia do jovem usuário de crack: mídia, justiça, saúde, educação. (Dissertação de Mestrado). Universidade Federal de Santa Maria, RS.

Oliveira, D. C., \& Dias, M. H. (2010). Os jovens usuários de crack e a rede de cuidados: problematizações a partir de uma experiência. In L. M. B. Santos (Org.), Outras palavras sobre o cuidado de pessoas que usam drogas (pp. 27-42). Porto Alegre, RS: Ideograf.

Oliveira, J. F. (2008). (In)visibilidade do consumo de drogas como problema de saúde num contexto assistencial: uma abordagem de gênero. (Tese de Doutorado). Instituto de Saúde Coletiva, Universidade Federal da Bahia, BA.

Pérez-Nebra, A. R., \& Jesus, J. G. (2011). Preconceito, estereótipo e discriminação. In C.V.Torres, \& E. R. Neiva (Orgs.), Psicologia social: principais temas e vertentes (pp. 219-237). Porto Alegre, RS: Artmed.

Pratta, E. M. M., \& Santos, M. A. (2009). O processo saúde-doença e a dependência química: interfaces e evolução. Psicologia: Teoria e Pesquisa, 25(2), 203-211. doi:10.1590/S0102-37722009000200008

Santos, M. F. S., Acioli Neto, M. L., \& Sousa, Y. S. O. (2012). Representações sociais do crack na imprensa pernambucana. Estudos de Psicologia, 29(3), 379-386. doi:10.1590/S0103-166X2012000300008

Totugui, M. (1988). Visão histórica e antropológica do consumo de drogas. In R. Bucher (Org.), As drogas e a vida: uma abordagem biopsicossocial (pp. 1-7). São Paulo, SP: EPU.
Tinoco, R. (2002). Forum: Para uma história dos efeitos das drogas: dos usos cerimoniais aos consumos malditos. Revista Antropológicas, 6, 221-245.

Vargas, D., Bittencourt, M. B., Rocha, F. M., \& Oliveira, M. A. F. (2013). Representação social de enfermeiros de centros de atenção psicossocial em álcool e drogas (CAPS AD) sobre o dependente químico. Escola Anna Nery, 17(2), 242-248. doi:10.1590/S1414-81452013000200006

Vargas, E. V. (1998). Os corpos intensivos: sobre o estatuto social do consumo de drogas legais e ilegais. In L. F. D. Duarte, \& O. F. LEAL, (Orgs.), Doença, sofrimento, perturbação: perspectivas etnográficas [online]. Rio de Janeiro, RJ: Fiocruz.

\section{Juliana Rízia Félix Melo}

Doutoranda em Psicologia Social pela Universidade Federal da Paraíba, João Pessoa - PB. Brasil.

E-mail: julianarizia@hotmail.com

\section{Silvana Carneiro Maciel}

Doutora em Psicologia Social pela Universidade Federal da Paraíba, João Pessoa - PB. Docente da Universidade Federal da Paraíba, João Pessoa - PB. Brasil.

E-mail: silcamaciel@gmail.com

\section{Endereço para envio de correspondência:} Universidade Federal da Paraíba. Cidade Universitária. CEP: 58059-900. João Pessoa - PB. Brasil.

Recebido 16/06/2014

Aprovado 20/01/2016

Received 06/16/2014

Approved 01/20/2016

Recibido 16/06/2014

Aceptado 20/01/2016

Como citar: Melo, J. R. F., \& Maciel, S. C. (2016). Representação social do usuário de drogas na perspectiva de dependentes químicos. Psicologia: Ciência e Profissão, 36(1): 76-87. doi:10.1590/1982-3703000882014

How to cite: Melo, J. R. F., \& Maciel, S. C. (2016). Drug User's Social Representation in the Perspective of the Chemical Dependent. Psicologia: Ciência e Profissão, 36(1): 76-87. doi:10.1590/1982-3703000882014

Cómo citar: Melo, J. R. F., \& Maciel, S. C. (2016). Representación Social del Usuario de Drogas en la Perspectiva de Dependientes Químicos. Psicologia: Ciência e Profissão, 36(1): 76-87. doi:10.1590/1982-3703000882014 